\title{
Pikiran Damai Berdasarkan Penuturan Markesot: Studi Hermeneutika Teks Markesot Bertutur Lagi
}

\author{
(Peaceful Thoughts Based on Markesot Advice: Study of the Hermeneutic Text of the Markesot \\ Bertutur Lagi (Markesot Speaks Again))
}

\author{
Wahyu Nanda Eka Saputra ${ }^{1}$, Agus Supriyanto ${ }^{1 *}$, Budi Astuti ${ }^{2}$, Yulia Ayriza ${ }^{2}$ \\ ${ }^{1}$ Program Studi Bimbingan dan Konseling, Fakultas Keguruan dan Ilmu Pendidikan, Universitas Ahmad Dahlan, \\ Jl. Pramuka No. 42, Yogyakarta, Daerah Istimewa Yogyakarta, 55161 Indonesia \\ ${ }^{2}$ Program Studi Bimbingan dan Konseling, Program Pascasarjana, Universitas Negeri Yogyakarta, \\ J1. Colombo No.1, Sleman, Yogyakarta, 55281 Indonesia \\ *corresponding author, email: agus.supriyanto@bk.uad.ac.id
}

Article received: November $29^{\text {th }} 2019$; revised: January $7^{\text {th }} 2020$; accepted: February $12^{\text {th }} 2020$

\begin{abstract}
This study aims to interpret peace based on a text entitled Markesot Bertutur Lagi by Emha Ainun Najib. This study used a qualitative approach with hermeneutics procedure. Each interpretation was an attempt to understand the meanings that are still veiled in a text. The data collection techniques in this study were carried out through the documentation of the interpretation of texts and literature studies. The interpretation was carried out in three stages: (1) whole understanding; (2) partial understanding; and (3) understanding of underlying meaning. The data analysis techniques in this study used the formulation of Miles \& Huberman which included data reduction, data presentation, and inference. The results showed that the peaceful mind based on Markesot Bertutur Lagi was: (1) thinking to forgive the mistakes of others; (2) thinking of finding strength rather than blaming yourself; (3) thinking to regulate self-emotions; and (4) thinking to regulate self-behavior. These four forms of peace of mind should be a reference for the school counselor to be the basis for implementing peace counseling to build peaceful thoughts in students.
\end{abstract}

Keywords: aggression; peaceful mind; Markesot; hermeneutics

\begin{abstract}
Abstrak: Penelitian ini bertujuan untuk menafsirkan pikiran damai berdasarkan teks yang berjudul Markesot Bertutur Lagi karya Emha Ainun Najib. Penelitian ini menggunakan pendekatan kualitatif dengan tipe hermeneutika. Setiap interpretasi adalah usaha untuk memahami makna-makna yang masih terselubung dalam sebuah teks. Teknik pengumpulan data dalam penelitian ini dilakukan melalui dokumentasi pemaknaan teks dan studi pustaka. Penafsiran dilakukan dalam tiga tahap, yaitu: (1) pemahaman keseluruhan (whole); (2) pemahaman bagian (part); dan (3) mendapatkan pemahaman pada yang melandasi makna (understanding of underlying meaning). Teknik analisis data dalam penelitian ini menggunakan rumusan dari Miles \& Huberman yang meliputi reduksi data, penyajian data, dan penyimpulan. Hasil penelitian menunjukkan bahwa pikiran damai berdasarkan penuturan Markesot adalah: (1) berpikir untuk memaafkan kesalahan orang lain; (2) berpikir untuk menemukan kekuatan diri daripada menyalahkan diri sendiri; (3) berpikir untuk meregulasi emosi diri; dan (4) berpikir untuk meregulasi perilaku diri. Keempat bentuk pikiran damai ini seyogianya menjadi rujukan konselor sekolah guna menjadi dasar pelaksanaan konseling kedamaian untuk membangun pikiran damai siswa.
\end{abstract}

Kata kunci: agresi; pikiran damai; Markesot; hermeneutika 


\section{PENDAHULUAN}

Masa remaja menjadi masa peralihan antara masa anak-anak menuju masa dewasa (Bjorklund \& Blasi, 2011; Dolgin \& Rice, 2011; Papalia et al., 2003). Pada masa ini anak mengalami berbagai perkembangan baik fisik, emosi, sosial, dan kognitifnya. Dalam tugas perkembangannya, remaja akan melewati beberapa fase dengan berbagai tingkat kesulitan permasalahan dan konflik. Pada masa ini, individu juga berada pada kondisi psikis yang sangat labil, karena masa ini merupakan fase pencarian jati diri (Hurlock, 2001; McCallum, 2012; Meeus, 2011; Wiley \& Berman, 2013). Remaja akan mencari tahu siapa dirinya dan bagaimana mereka harus berperan di lingkungannya.

Namun demikian, remaja usia sekolah memiliki berbagai masalah, utamanya berkaitan dengan emosi. Salah satu masalah terkait dengan emosi siswa adalah perilaku agresi. Sebuah penelitian menunjukkan bahwa Siswa Sekolah Menengah Kejuruan (SMK) di Yogyakarta yang melakukan perilaku agresi kategori sangat tinggi sebesar 4\%, kategori tinggi sebesar $26 \%$, kategori sedang sebesar 40\%, kategori rendah sebesar 21\%, dan kategori sangat rendah sebesar 8\% (Saputra \& Handaka, 2018). Pada siswa Sekolah Menengah Pertama (SMP) di Daerah Istimewa Yogyakarta (DIY) diketahui 1\% siswa memiliki agresivitas yang sangat tinggi, 13\% kategori tinggi, 37\% kategori sedang, 43\% kategori rendah, dan 6\% kategori sangat rendah (Alhadi et al., 2018). Penelitian lain menunjukkan $72 \%$ siswa melakukan serangan fisik kepada ibu mereka dan 38\% menyerang atau mengancam ayah mereka (Routt \& Anderson, 2011). Lebih jauh, pola agresivitas remaja laki-laki dan perempuan di SMK Kota Yogyakarta juga cenderung sama (Saputra et al., 2017).

Salah satu bentuk perilaku agresi yang sedang hangat dibicarakan di Yogyakarta adalah fenomena klithih (Febriani, 2018). Fenomena klithih telah menjadi kegaduhan sosial di Yogyakarta karena menyebabkan banyaknya korban jiwa (Sarwono, 2017). Fenomena ini menjadi permasalahan bagi remaja usia sekolah karena mereka melakukan bentuk kekerasan fisik kepada remaja lain dengan menggunakan celurit, gir, palu, dan sebagainya. Kekerasan tersebut biasanya dilakukan dengan mengendarai sepeda motor. Korban yang dikenai juga acak dan pelaku tidak memiliki alasan khusus ketika melukai korban. Pelaku klithih ini menggunakan berbagai strategi agar perilakunya tidak mudah diketahui oleh orang lain, termasuk polisi, antara lain: (1) bertindak pada malam hari; (2) menemukan tempat yang tenang; (3) menggunakan aksesori; (4) melepas pelat nomor pada sepeda motor untuk menghindari penangkapan CCTV; (5) menghafal medan; dan (6) membangun solidaritas geng (Sarmini et al., 2018).

Bentuk-bentuk perilaku agresi yang dilakukan oleh remaja usia sekolah tersebut dapat berdampak negatif terhadap dirinya sendiri dan orang lain. Salah satu dampaknya adalah mendorong munculnya persepsi pada diri siswa tentang tidak kondusifnya iklim sekolah tempat mereka belajar (Klein et al., 2012; Nickerson et al., 2014; Steffgen et al., 2013). Persepsi buruk siswa terhadap iklim sekolah berpengaruh signifikan terhadap keterlibatan siswa dalam belajar (Cornell et al., 2016; Einarsen et al., 2018; Mehta et al., 2013) dan performa akademik siswa di kelas (Benbenishty et al., 2016; Makewa et al., 2011). Dampak lain yang terlihat dari munculnya persepsi buruk tentang iklim sekolah sebagai akibat dari perilaku agresi adalah menurunnya prestasi akademik siswa di sekolah (Benbenishty et al., 2016; Makewa et al., 2011; Milam et al., 2010; Wang et al., 2014).

Salah satu upaya yang dapat dilakukan konselor sekolah adalah mengembangkan layanan bimbingan dan konseling guna mengembangkan pikiran damai siswa. Hal ini dilakukan agar tercipta pikiran damai siswa dan siswa mampu meminimalisir perilaku agresinya. Kedamaian berada dalam pikiran setiap manusia yang perlu dikembangkan oleh setiap manusia (Anand, 2014). Pikiran damai ditandai dengan kondisi perasaan yang tenang dari dalam diri dan harmoni (Lee et al., 2013). Pikiran damai dapat mendorong siswa untuk menjalani kehidupan sesuai dengan keinginan dan pilihannya sendiri dan juga dinilai oleh diri sendiri, sehingga kehidupan siswa dapat tumbuh lebih baik dan konstruktif (Hill, 2007). Pikiran damai yang tertanam pada remaja akan menjadi unsur yang dapat mencegah remaja melakukan perilaku agresi.

Terdapat beberapa pendapat yang menyebutkan bahwa pikiran damai dapat mencegah remaja berperilaku agresi. Penelitian yang dilakukan di Turki menyimpulkan bahwa pendidikan kedamaian yang fokusnya pada pembangunan pikiran damai siswa dapat secara efektif meningkatkan empati siswa (Sagkal et al., 2012). Empati inilah yang mendorong siswa untuk tidak menunjukkan perilaku agresi (Eisenberg et al., 2010; Van der Graaff et al., 2012). Perilaku agresi dan kekerasan di sekolah perlu untuk diatasi, salah satunya dengan cara membangun pikiran damai siswa (Greene, 2005). 
Pikiran damai remaja bisa dikembangkan melalui hasil analisis suatu teks, salah satunya yaitu menggunakan teks berjudul Markesot Bertutur Lagi. Teks Markesot Bertutur Lagi merupakan buku kedua, lanjutan dari teks Markesot Bertutur yang merupakan buku pertama. Markesot adalah penjelmaan sahabat Emha Ainun Nadjib dan Emha Ainun Nadjib itu sendiri (Nadjib, 2012). Markesot merupakan sosok lugu, cerdas dan misterius. Markesot banyak memperbincangkan masalah yang sering terjadi di masyarakat. Kehidupan Markesot dapat membawa remaja menanamkan pemikiran damai yang dapat menghindarkan remaja berperilaku agresi.

Penelitian ini berusaha untuk menafsirkan buku karangan Emha Ainun Najib yang berjudul Markesot Bertutur Lagi. Karakteristik pikiran damai dari tokoh Markesot akan ditafsirkan dengan penelitian pendekatan kualitatif dengan jenis Hermeneutika. Pikiran damai hasil penafsiran dari teks Markesot Bertutur Lagi yang berbentuk sebuah konsep dapat dikembangkan menjadi sebuah buku panduan yang bisa membantu diri remaja sendiri (self help) melatih berpikir damai berdasarkan teks Markesot Bertutur Lagi.

\section{METODE}

Penelitian ini menggunakan pendekatan kualitatif dengan metode hermeneutika. Penggunaan metode hermeneutika dikarenakan hermeneutika mengambil peran mengupas makna tersembunyi dalam sebuah teks. Setiap interpretasi adalah usaha untuk memahami makna-makna yang masih terselubung dalam sebuah teks. Penelitian ini ingin melihat representasi pikiran damai siswa dengan menetapkan cara kerja lingkaran hermeneutika untuk mendapatkan pemahaman yang optimal, sehingga hermeneutika mampu merepresentasi pikiran damai siswa berdasarkan teks Markesot Bertutur Lagi. Lingkaran secara keseluruhan mendefinisikan bagian-bagian dan bagian-bagian bersama membentuk lingkaran. Satu kalimat utuh misalnya, merupakan satu kesatuan. Secara spesifik, peneliti menggunakan hermeneutika Gadamerian dalam menemukan makna di balik teks Markesot Bertutur Lagi.

Jenis data pertama yang digunakan dalam penelitian ini adalah data sekunder. Data sekunder dalam penelitian ini adalah teks Markesot Bertutur Lagi yang terdiri dari sembilan bagian (chapter). Peneliti menggunakan data yang bersumber dari isi yang ada dalam teks. Data sekunder dalam penelitian ini dianalisis dengan membaca, dan mengutip sumber-sumber tertulis seperti buku, artikel, kamus, jurnal, dan sumber lain dari internet yang berkaitan dengan penelitian.

Teknik pengumpulan data dalam penelitian ini dilakukan melalui dokumentasi pemaknaan teks. Peneliti mencoba menafsirkan pikiran damai berdasarkan teks Markesot Bertutur Lagi melalui tiga tahap, yaitu: (1) pemahaman keseluruhan (whole); (2) pemahaman bagian (part); dan (3) mendapatkan pemahaman pada yang melandasi makna (understanding of underlying meaning) (Mappiare, 2013). Teknik analisis data dalam penelitian ini meliputi reduksi data, penyajian data, dan penyimpulan (Miles \& Huberman, 1994).

\section{HASIL}

Hasil penelitian menunjukkan bahwa pikiran damai remaja yang diadopsi dari teks Markesot Bertutur Lagi adalah: (1) berpikir untuk memaafkan kesalahan orang lain; (2) berpikir untuk menemukan kekuatan diri daripada menyalahkan diri sendiri; (3) berpikir untuk meregulasi emosi diri, dan (4) berpikir untuk meregulasi perilaku diri. Adapun hasil penelitian tersebut ditabulasikan dalam tabel 1.

Berpikir untuk memaafkan, konsep berpikir ini merupakan suatu kondisi di mana manusia seringkali disakiti, tetapi mereka akan memaafkan perbuatan orang lain yang menyakiti. Bahkan jika perlu, walaupun pihak yang menyakiti tidak memaafkan, manusia perlu memaafkannya. Markesot mengalami hal ini dan lebih memilih untuk mengalah. Markesot memaafkan orang yang meremehkannya, walaupun orang yang meremehkan tersebut tidak meminta maaf bahkan memikirkan untuk meminta maaf.

Markesot hanya memandang setiap manusia itu sama, tidak ada perbedaan antara Bupati dan Penjual Dawet, antara Cendekiawan dan Karyawan Bengkel, yang membedakan hanyalah baktinya di hadapan Allah (12).

Markesot diremehkan tidak sekali saja. Markesot juga pernah diremehkan ketika diberi kesempatan untuk membaca ayat suci Al-Quran. Dalam kesempatan tersebut, Markesot banyak diragukan dan 
Tabel 1. Pikiran Damai Penuturan Markesot

\begin{tabular}{cllc}
\hline No & \multicolumn{1}{c}{ Klasifikasi } & \multicolumn{1}{c}{ Keterangan } & \multicolumn{1}{c}{ Kode } \\
\hline 1 & $\begin{array}{l}\text { Berpikir untuk memaafkan } \\
\text { kesalahan orang lain }\end{array}$ & $\begin{array}{l}\text { Jika saya disakiti, maka saya akan } \\
\text { memaafkan }\end{array}$ & $12,18 \mathrm{a}, 29,82$ \\
2 & $\begin{array}{l}\text { Berpikir untuk menemukan } \\
\text { kekuatan diri daripada } \\
\text { menyalahkan diri sendiri }\end{array}$ & $\begin{array}{l}\text { Jika saya dilihat dari sisi negatif saya, maka } \\
\text { saya akan mencari sisi positif saya }\end{array}$ & $18 \mathrm{~b}, 22,59,134,217$ \\
3 & $\begin{array}{l}\text { Berpikir untuk meregulasi } \\
\text { emosi diri }\end{array}$ & $\begin{array}{l}\text { Jika saya tersakiti, maka saya akan berdamai } \\
\text { dengan diri saya agar tidak terlampiaskan } \\
\text { pada orang lain }\end{array}$ & $52,72,220,257$ \\
4 & $\begin{array}{l}\text { Berpikir untuk meregulasi } \\
\text { perilaku diri }\end{array}$ & $\begin{array}{l}\text { Saya akan mandiri pada diri saya sendiri } \\
\text { untuk tidak menunjukkan perilaku } \\
\text { menyakitkan bagi orang lain }\end{array}$ & $83,114,123,161$ \\
\hline
\end{tabular}

ditertawakan orang lain, bahkan banyak yang sulit membayangkan bagaimana bentuk dan praktiknya Markesot melantunkan ayat suci Al-Quran.

Akan tetapi Markesot hanya diam dan mampu membaca Al-Quran dengan baik serta membuat hadirin yang semula kemriyek seperti pasar, mendadak terdiam. Bahkan beberapa ibu-ibu menangis dan yang lainnya memilih menundukkan muka (82).

Hal ini menunjukkan bahwa Markesot lebih memilih untuk memaafkan orang yang menghinanya dan menampilkan dirinya dengan sebaik mungkin daripada harus banyak berurusan dengan orang yang meremehkannya.

Selain diremehkan, manusia seringkali diberikan label tertentu. Label negatif lebih mudah diberikan oleh manusia daripada label positif. Apabila seseorang yang diberi label negatif tidak berkenan, hal ini akan mendorong terjadinya permusuhan. Tetapi hal ini tidak berlaku bagi Markesot yang berupaya untuk tetap tersenyum dan memberikan maaf apabila Markesot diberikan label negatif sekalipun. Hal ini terjadi pada Markesot ketika ia diberi label sebagai "dukun global" atau "dukun era globalisasi" oleh Markembloh. Label tersebut tentunya label yang tidak disukai dan tidak diinginkan oleh Markesot.

Mendapat label tersebut Markesot hanya tersenyum sesaat, kemudian wajahnya kembali dingin dan angker (29).

Hal itu menandakan Markesot tidak ingin mencari permusuhan yang berlebihan dan memilih untuk memaafkan Markembloh.

Niatan seseorang untuk meminta maaf dan memberi maaf menjadi unsur penting dalam terciptanya kedamaian. Hal ini akan mengurangi berbagai macam gesekan antar kelompok tertentu yang berujung pada munculnya kekerasan yang merugikan berbagai pihak. Markesot melakukan hal ini pada hari kedua di bulan Syawal.

Markesot membuka pintu rumah pagi-pagi dan menemui tetangganya untuk saling bermaaf-maafan (18).

Ini dilakukan untuk mewujudkan keharmonisan antar warga masyarakat dan mengurangi perasaan saling tidak nyaman yang bisa jadi menjadi salah satu sumber munculnya kekerasan.

Bentuk pola pikir damai Markesot yang kedua adalah berpikir untuk menunjukkan kekuatan daripada kelemahan yang dimiliki. Hal ini dilakukan Markesot untuk mencari dan menunjukkan kebaikan dalam dirinya daripada harus meributkan kelemahan yang menjadi cacian dan hinaan orang lain. Hal ini menunjukkan bahwa Markesot bisa membuktikan dirinya dapat meredam permusuhan yang memiliki kemungkinan terjadi perselisihan dengan orang di sekitarnya.

Markesot dianggap sebagai orang yang kaku dan mungkin sedikit terbelakang. Hal tersebut tak lain karena Markesot jarang memakai baju baru, termasuk ketika hari raya. Dalam situasi tersebut, Markesot hanya tersenyum dan berpikir untuk mencari kekuatan yang ada dalam dirinya dengan harapan cara pandangnya tersebut bisa diterima oleh orang lain dan mereka dapat memaklumi sikap yang ditunjukkan Markesot. Terkait dengan sindiran orang di sekitar Markesot yang mengatakan bahwa Markesot hanya memakai baju "yang itu-itu saja", Markesot mencoba untuk mencari kekuatan di balik cara pandangnya. 
Pertama, "Bajuku tidak perlu baru, tetapi caraku memandang, menilai, dan memperlakukan baju Insya

Allah baru. Kedua, baju saya tetap baju yang kemarin-kemarin, karena kamu tidak pernah punya inisiatif untuk membelikan saya baju" (18).

Cara berpikir yang berupaya untuk menunjukkan kekuatan dari kelemahan yang dimiliki, juga tampak ketika Markesot mendapat argumen dari orang lain bahwa antar manusia itu ada perbedaan strata yang membuat seseorang harus memperlakukan orang yang lebih tinggi stratanya dengan cara yang lebih baik, sesuai dengan stratanya. Hal ini dibantah oleh Markesot bahwa manusia jika dipandang dengan menggunakan cara pandangnya manusia, maka jelas akan berbeda. Tetapi sejatinya jika dihadapan Tuhan, semuanya sederajat. Markesot juga mengatakan bahwa,

"Saya bisa juga menunduk-nunduk, asalkan orang lain juga melakukan hal yang sama sebagai suatu bentuk penghormatan kepada sesama" (22).

Maksud dari pernyataan Markesot ini tentu meminimalisir adanya kekesalan antar manusia apabila mereka dibedakan berdasarkan strata sosial yang mengharuskan mereka untuk memperlakukan orang yang lebih tinggi strata sosialnya dengan cara yang berbeda.

Kisah lain tentang Markesot dalam upayanya mencari kebaikan manusia dari pada kelemahan manusia juga ditunjukkan ketika banyak orang menyindir dan menganggap sebelah mata karya pak Zein yang dalam perjalanannya berhasil mendirikan kelompok musik kasidah. Hasil jerih payah pak Zein ini seringkali disindir dan bahkan direndahkan oleh orang lain. Ada yang menganggap mendangkalkan religiusitas, lirik-liriknya dianggap kampungan, dan bahkan terkesan menjadi beban pembangunan negeri ini. Tetapi dibalik itu, Markesot berpikir lain, yaitu mencari kekuatan dari musik kasidah yang didirikan oleh pak Zein.

"Pak Zein termasuk pelopor aksi kebudayaan islam, tatkala kebanyakan orang islam hanya sibuk mendiskusikan dan mengharam-haramkan" (59).

Pola pikir Markesot tersebut memberi isyarat bahwa kekuatan yang dimiliki pak Zein adalah bagaimana perannya ikut andil dalam berperang dalam bidang kebudayaan dengan cara meneladankan etos kerja melalui pesantren musik.

Kisah lain yang menunjukkan bagaimana Markesot berpikir damai yaitu ketika merespon berbagai serangan dunia barat di negara-negara timur, termasuk Indonesia. Serangan yang pasti terlihat adalah bagaimana jenis-jenis barang seperti fried chicken, McDonald's dan barang-barang lain masuk ke Indonesia, bahkan tidak hanya di kota, tetapi juga di daerah. Barang-barang tersebut menyingkirkan barang-barang lokal seperti bol cino, rondo kemul, dan sebagainya. Banyak orang yang bersuara dan cenderung memeranginya dengan suara lantang.

Markesot lebih memilih mencari kebaikannya dengan cara menikmati situasi yang ada dengan tetap mencari jalan agar barang-barang asli dari Indonesia mampu bertahan di tengah gempuran westernisasi (134).

Markesot memiliki cara pandang yang berbeda terhadap hakikat orang kecil di Indonesia. Orang kecil didefinisikan sebagai orang yang tidak berpendidikan dan cara pandang yang dangkal. Sehingga, seringkali mereka dianggap sebagai orang yang sembarangan dalam berpikir. Tetapi dalam kisahnya, justru Markesot memandang di balik cara pandang orang kecil yang dangkal, tersimpan kekuatan dan keaslian sebagai seorang manusia.

Orang kecil tidak dibatasi memiliki cara pandang yang kompleks dan bertele-tele (217).

Apa yang mereka pikirkan dan suarakan adalah murni perasaan dan peristiwa yang mereka alami tanpa ada embel-embel untuk "dibuat-buat". Justru dari cara pandang mereka yang dianggap dangkal, terkuat peristiwa yang sebenarnya terjadi pada masyarakat di Indonesia.

Bentuk pola pikir damai Markesot yang ketiga adalah berpikir untuk meregulasi emosi diri. Bentuk pola pikir yang ketiga ini ditunjukkan Markesot ketika memaknai keadaan diam itu sendiri, Markesot menyebutnya sebagai road of silence. Dikisahkan terjadi berbagai ketidaksetujuan dan perbedaan pendapat, beberapa orang mengatakan yang dilihatnya adalah baik, tetapi beberapa orang yang lain melihatnya sebagai sesuatu yang buruk. Beberapa orang melihatnya sebagai setan, tetapi beberapa orang yang lain melihatnya sebagai wakil Tuhan. Berbagai ketidaksetujuan dan perbedaan ini terus disuarakan dan bahkan sebagai pemicu perpecahan dan kekerasan. Tetapi Markesot tetap pada pendiriannya, road of silence. 
Lebih baik berpikir untuk diam dan dalam kediamannya memendam amarah yang ingin dikeluarkan (52).

Hal ini menyiratkan bahwa kemampuan manusia untuk meregulasi emosi ditunjukkan dengan diam daripada terus menjawab dan merespon orang lain yang memiliki pendapat yang berbeda.

Lebih jauh, Markesot juga mengatakan bahwa seseorang sejatinya adalah raja bagi dirinya sendiri (72).

Pertikaian antar pihak menjadi hiasan yang terus menghiasi pemberitaan nasional Indonesia akhirakhir ini. Bahkan untuk menunjukkan partisipasi mereka dan agar tidak disebut sebagai manusia tanpa pegangan, mereka rela menjadi relawan dan saling hantam.

Markesot membenarkan bahwa, "Memang agak sayang kita tidak terlibat peperangan melawan bangsa atau negara manapun, sehingga naluri kita sebagai sukarelawan tidak terpenuhi" (220).

Akan tetapi untuk meminimalisir kondisi pertikaian antar kedua belah pihak, terkadang bertarung dengan diri sendiri menjadi hal yang perlu dilakukan. Bertarung yang dimaksud adalah bagaimana memerangi keinginan dan naluri manusia untuk tidak menyakiti orang lain, baik sengaja maupun tidak sengaja.

Terdapat kisah lain dari Markesot tentang bagaimana berpikir damai dengan cara meregulasi emosinya. Menurut Markesot, terdapat perbedaan antara hal dan maqam.

Hal adalah suatu keadaan, suatu bakat, kecenderungan atau genuisitas yang dianugerahkan oleh Allah kepada seseorang. Maqam adalah suatu titik orbit yang diperjuangkan untuk dicapai. Dalam spektrum khalqillah hukum penciptaan oleh Allah, Maqam tertinggi adalah jika seseorang telah berjumpa dengan hal-nya, dan itulah yang terbaik, tertinggi, dan termulia bagi setiap manusia (257).

Bentuk pola pikir damai keempat dari Markesot adalah berpikir untuk meregulasi perilaku diri. Markesot memandang bahwa manusia memiliki kemampuan untuk mengatur perilakunya sendiri sesuai dengan kehendak dan bagaimana berpikir. Hal tersebut dinyatakan Markesot dengan kalimat

"Untuk melatih menaklukkan kehendak, mengatasi kemauan, mengalahkan nafsu, karena kami tidak mau menjadi manusia modern yang menyembah egosentrisme diri dengan menomorduakan Allah dan orang lain" (114).

Kebebasan berperilaku menjadi prinsip hidup yang dimiliki Markesot. Cara pandang Markesot tentang kebebasan berperilaku juga ditunjukkan dengan pernyataan bahwa,

"Markesot adalah pemuja kebebasan. Penganjur kemerdekaan berpendapat, dan dengan demikian juga kemerdekaan pers" (123).

Dalam pernyataan tersebut, tentu menjadi penting bagi Markesot untuk memiliki kebebasan dalam menunjukkan perilaku tertentu. Kebebasan yang dimaksud Markesot bukanlah kebebasan yang tanpa batas, tetapi kebebasan yang tetap terikat.

Markesot juga menunjukkan pola pikir ini ketika Markesot diundang oleh Markaban untuk mengaji. Sontak undangan tersebut membuat banyak pihak tercengang dan seakan tidak percaya terhadap undangan tersebut.

Sikap yang ditunjukkan oleh Markesot tidak serta merta tersinggung pada pihak tersebut, Markesot tetap mengaji dengan tidak pamer kebolehan, pamer nafas panjang, pamer dialek, pamer nada dan oktaf kepada pendengarnya. Markesot berupaya menampilkan diri dengan perilaku mengaji dengan mengandalkan getaran batinnya dan mengomunikasikan vibrasi keilahian (83).

Bentuk perilaku yang ditunjukkan Markesot tidak lantas membalas penilaian negatif orang lain dengan perilaku yang jauh tidak menyenangkan, tetapi Markesot lebih memilih untuk menunjukkan keaslian perilakunya, terutama dalam hal ini adalah ketika membaca Al Quran.

Markesot tidak hanya menuntut dirinya untuk memiliki pikiran damai, namun juga mengatur perilaku jika hendak ingin menyakiti orang lain, juga mendorong dan membelajarkan orang lain untuk turut mengatur perilaku mereka ketika hendak melakukan tindak kekerasan pada orang lain. Hal ini ditunjukkan Markesot dengan pernyataan

"Jangan marah kepada saya. Kalau mau marah, marahlah pada realitas yang saya bawa ini. Jangan

demokrasi kepada saya, tetapi unjuk rasalah kepada pihak yang merilis produk-produk ini” (161). 


\section{PEMBAHASAN}

Temuan penelitian ini menunjukkan bahwa terdapat empat bentuk pola pikir damai berdasarkan penuturan Markesot. Pertama, berpikir untuk memaafkan kesalahan orang lain, yaitu jika saya disakiti, maka saya akan memaafkan. Kedua, berpikir untuk menemukan kekuatan diri daripada menyalahkan diri sendiri, yaitu jika saya dilihat dari sisi negatif saya, maka saya akan mencari sisi positif saya. Ketiga, berpikir untuk meregulasi emosi diri, yaitu jika saya tersakiti, maka saya akan berdamai dengan diri saya agar tidak terlampiaskan pada orang lain. Keempat, berpikir untuk meregulasi perilaku diri, yaitu saya akan berdaulat pada diri saya sendiri untuk tidak menunjukkan perilaku menyakitkan bagi orang lain.

Pola pikir damai yang terdiri dari empat bentuk ini menjadi indikasi bahwa berpikir damai menjadi variabel penting bagi manusia termasuk remaja untuk dapat menciptakan kedamaian tanpa harus memunculkan kekerasan. Kedamaian yang tercipta tanpa harus memunculkan kekerasan ini termasuk dalam konsep kedamaian positif (Galtung, 1967). Konsep kedamaian ini menjadi sebuah konsep kedamaian yang sejati dan diinginkan oleh masyarakat luas. Kedamaian positif akan lebih efektif jika ditempuh melalui latar pendidikan, yang sering disebut dengan pendidikan kedamaian (Fountain, 1999).

Berbagai penelitian menunjukkan bahwa pembangunan pikiran damai melalui latar pendidikan ini dapat dilakukan secara efektif. Hasil penelitian menunjukkan bahwa implementasi pendidikan kedamaian dapat membantu siswa meminimalisir terjadinya konflik antar siswa yang dapat merugikan kedua belah pihak (Tidwell, 2004). Temuan penelitian lain juga menyebutkan bahwa program pendidikan kedamaian dapat secara efektif memengaruhi kepercayaan remaja untuk tidak memunculkan konflik dengan orang lain (Rosen \& Salomon, 2011). Penelitian lain juga menyebutkan bahwa pendidikan kedamaian dapat mendorong remaja untuk memiliki keterampilan untuk berempati kepada orang lain (Sagkal et al., 2012). Keterampilan empati yang dimiliki oleh remaja inilah yang dapat menjadi salah satu faktor pendukung muncul atau tidaknya perilaku agresi pada remaja (Bartholow et al., 2005; Kaukiainen et al., 1999).

Bentuk pola pikir damai berdasarkan penuturan Markesot yang pertama adalah berpikir untuk memaafkan kesalahan orang lain. Konsep memaafkan menjadi satu variabel penting yang perlu dimiliki remaja saat ini. Terlebih lagi, kemungkinan terjadi konflik sangat tinggi dan hampir pasti berpotensi terjadi pada setiap remaja. Memaafkan sendiri berkaitan dengan empati. Seseorang yang kurang memiliki empati, maka cenderung sulit untuk memaafkan, sebaliknya, seseorang yang memiliki kemampuan berempati, maka cenderung lebih mudah memaafkan (Macaskill et al., 2002).

Berpikir untuk dapat memaafkan sendiri berdasarkan hasil penelitian dapat secara efektif meminimalisir terjadinya kekerasan di sekolah. Hasil penelitian menunjukkan bahwa pemaafan menjadi salah satu unsur yang dapat mengendalikan seseorang untuk berperilaku agresi atau tidak (Moore \& Dahlen, 2008). Penelitian lain juga menunjukkan bahwa pemaafan dapat mereduksi perilaku agresi remaja usia 11-13 tahun di kota Dezful (Lavafpour Noori et al., 2012). Selain di sekolah, pemaafan juga dapat dimaksimalkan untuk latar luar sekolah. Seperti halnya di Tiongkok, pemaafan menjadi intervensi positif untuk mereduksi kemarahan pengemudi bus (Feng et al., 2018).

Bentuk pola pikir damai berdasarkan penuturan Markesot yang kedua adalah berpikir untuk menemukan kekuatan diri daripada menyalahkan diri sendiri. Setiap manusia pasti memiliki kekuatan dibalik kelemahan yang dimilikinya. Akan tetapi, akan lebih efektif apabila manusia lebih cenderung melihat kekuatan daripada kelemahannya. Dalam konseling juga diharapkan konselor dapat membangun pola pikir konseli untuk tetap melihat kelebihannya daripada kelemahannya atau sering disebut dengan strength based counseling (Kaczmarek, 2006; Park \& Peterson, 2008; Smith, 2006b, 2006a; Steiner, 2009; Ungar, 2006; White, 2002).

Seseorang yang berupaya berpikir tentang kekuatannya akan mencari kekuatan dibalik kelemahan mereka ketika dikerdilkan oleh orang lain. Hal ini akan membuat siswa menjadi pribadi yang tidak terus-menerus menjadi bahan ejekan orang lain dan mampu menunjukkan dirinya adalah pribadi yang mampu. Siswa yang berupaya berpikir tentang kekuatannya daripada harus berserah pada kelemahannya, merupakan sosok siswa yang memiliki harapan dan optimisme ketika dihadapkan situasi sulit. Dengan bahasa sederhana, harapan dan optimisme adalah indikator siswa yang berfilosofi pada kekuatan diri (Valle et al., 2006). 
Bentuk pola pikir damai berdasarkan penuturan Markesot yang ketiga adalah berpikir untuk meregulasi emosi diri. Berpikir untuk meregulasi emosinya ketika dihadapkan pada situasi yang berpotensi memun-culkan perilaku agresi merupakan bagian penting yang dapat dilakukan oleh remaja demi terwujudnya kedamaian yang hakiki. Munculnya regulasi emosi membuat seseorang yang dijadikan objek kekerasan memilih untuk mengalah dan menurunkan egonya daripada harus meladeni tindakan kekerasan yang dilakukan oleh orang lain. Dengan bahasa sederhana, regulasi emosi dapat mereduksi kecenderungan seseorang memunculkan perilaku agresi (García-Sancho et al., 2017; Renati et al., 2011; Roberton et al., 2012).

Seseorang yang mampu berpikir untuk mengoptimalkan kemampuan regulasi emosinya menjadi salah satu indikasi bahwa ia memiliki kecerdasan emosi yang tinggi (García-Sancho et al., 2017). Hal ini menjadi modal besar seorang remaja untuk menjadi pribadi yang sukses dalam kehidupannya sendiri dan di hadapan orang lain. Sesungguhnya, berpikir untuk melakukan regulasi emosi adalah wujud seseorang untuk berdaulat terhadap perasaannya masing-masing dan berdamai dengan diri sendiri serta orang lain.

Bentuk pola pikir damai berdasarkan penuturan Markesot yang keempat adalah berpikir untuk mere-gulasi perilaku diri. Wujud dari pola pikir ini adalah bagaimana Markesot menjunjung sebuah kebebasan. Kebebasan yang dimaksud bukan bebas melakukan tindakan apapun tanpa batas, tetapi kebebasan yang terikat dan terbatas oleh keimanan (Afshah, 1996). Kebebasan yang terikat itu sendiri seringkali dilupakan oleh remaja masa kini sehingga remaja cenderung melakukan sesuatu sesuai dengan prinsip rasa senang dan keinginan dari remaja tersebut.

Konsep berpikir damai Markesot yang keempat ini sesuai dengan konsep self-regulation pada diri manusia. Konsep tersebut bermakna bahwa manusia memiliki kemampuan untuk mengatur perilakunya sesuai dengan keinginan dan nilai yang dipegang oleh manusia tersebut (Bandura, 1991; Baumeister et al., 1994; Zimmerman, 2000). Keterampilan ini juga menjadi salah satu keterampilan yang perlu dimiliki remaja untuk menunjang remaja menuju identitas sukses. Self-regulation sendiri menjadi variabel penting untuk menunjang manusia untuk berpikir damai dan tidak menunjukkan perilaku agresi (DeWall et al., 2007; Healey, 1967; Keller et al., 2008).

Pikiran damai menurut Markesot yang menjadi temuan dalam penelitian ini memiliki implikasi dalam pemberian pelayanan bimbingan dan konseling. Bentuk-bentuk pikiran damai berdasarkan Markesot dapat digunakan konselor untuk melatih siswa agar memiliki kedamaian pikiran ketika menghadapi situasi yang dapat berpotensi memicu munculnya kekerasan. Terlebih, salah satu contoh kekerasan remaja, yaitu perilaku agresi yang semakin kompleks dan semakin beragam bentuknya (Alhadi et al., 2018; Saputra \& Handaka, 2018). Bahkan perilaku agresi siswa SMK berjenis kelamin laki-laki dan perempuan di Yogyakarta memiliki kecenderungan sama (Saputra et al., 2017).

Berdasarkan permasalahan-permasalahan kekerasan yang dilakukan siswa saat ini, konselor dapat memberikan pelayanan bimbingan dan konseling yang bertujuan untuk membangun kedamaian pikiran siswa, sehingga perilaku agresi pada siswa dapat ditekan. Hal ini dilakukan dengan asumsi bahwa kedamaian berpikir manusia memiliki keterkaitan dengan kekerasan atau perilaku agresi yang dilakukan oleh manusia (Kartadinata et al., 2015), dimana berbagai perilaku kekerasan yang dilakukan siswa di sekolah, memiliki dampak yang buruk terhadap performa akademik yang ditampilkan siswa di kelas. Upaya konselor sekolah untuk melatih siswa memiliki kedamaian berpikir pada diri siswa agar terhindar dari meluapnya agresivitas siswa disebut dengan bimbingan kedamaian (Saputra et al., 2019). Selain itu, upaya konselor untuk membangun kedamaian berpikir manusia melalui sesi konseling yang bertujuan untuk menekan perilaku agresi yang tekah muncul pada diri manusia disebut dengan konseling kedamaian (Saputra \& Handaka, 2017).

\section{SIMPULAN}

Pikiran damai menjadi salah satu kemampuan yang perlu dimiliki oleh siswa. Hal ini sebagai modal siswa untuk menghindarkan diri dari perilaku maladaptif seperti perilaku agresi. Berdasarkan identifikasi dari teks Markesot Bertutur Lagi, setidaknya terdapat empat pola berpikir damai pada diri siswa, yaitu: (1) berpikir untuk memaafkan kesalahan orang lain; (2) berpikir untuk menemukan kekuatan diri daripada menyalahkan diri sendiri; (3) berpikir untuk meregulasi emosi diri; dan (4) berpikir untuk meregulasi perilaku diri. Keempat bentuk pola pikir damai berdasarkan perspektif Markesot diharapkan dapat menjadi bahan kajian siswa untuk dapat membantu dirinya sendiri (self-help) untuk dapat mereduksi 
perilaku agresi yang sering muncul pada diri mereka. Penelitian ini seyogianya dapat menjadi dasar penelitian lanjutan seperti pengembangkan paket bimbingan dan konseling untuk mengembangkan pikiran damai siswa.

\section{DAFTAR RUJUKAN}

Afshah, H. (1996). Faith and freedom: Women's human rights in the Muslim world. Development in Practice, 6(3), 272-278.

Alhadi, S., Purwadi, P., Muyana, S., Saputra, W. N. E., \& Supriyanto, A. (2018). Agresivitas siswa SMP di Yogyakarta. Jurnal Fokus Konseling, 4(1), 93-99.

Anand, S. (2014). The contemporary issues and significance of peace education in India. International Journal of Research in Humanities, Arts and Literature, 2(10), 47-54.

Bandura, A. (1991). Social cognitive theory of self-regulation. Organizational Behavior and Human Decision Processes, 50(2), 248-287.

Bartholow, B. D., Sestir, M. A., \& Davis, E. B. (2005). Correlates and consequences of exposure to video game violence: Hostile personality, empathy, and aggressive behavior. Personality and Social Psychology Bulletin, 31(11), 1573-1586.

Baumeister, R. F., Heatherton, T. F., \& Tice, D. M. (1994). Losing control: How and why people fail at selfregulation. Academic press.

Benbenishty, R., Astor, R. A., Roziner, I., \& Wrabel, S. L. (2016). Testing the causal links between school climate, school violence, and school academic performance: A cross-lagged panel autoregressive model. Educational Researcher, 45(3), 197-206.

Bjorklund, D. F., \& Blasi, C. H. (2011). Child and adolescent development: An integrated approach. Nelson Education.

Cornell, D., Shukla, K., \& Konold, T. R. (2016). Authoritative school climate and student academic engagement, grades, and aspirations in middle and high schools. AERA Open, 2(2), 2332858416633184.

DeWall, C. N., Baumeister, R. F., Stillman, T. F., \& Gailliot, M. T. (2007). Violence restrained: Effects of selfregulation and its depletion on aggression. Journal of Experimental Social Psychology, 43(1), 62-76.

Dolgin, K. G., \& Rice, F. P. (2011). The adolescent: Development, relationships, and culture. Allyn \& Bacon Boston, MA.

Einarsen, S., Skogstad, A., Rørvik, E., Lande, Å. B., \& Nielsen, M. B. (2018). Climate for conflict management, exposure to workplace bullying and work engagement: A moderated mediation analysis. The International Journal of Human Resource Management, 29(3), 549-570.

Eisenberg, N., Eggum, N. D., \& Di Giunta, L. (2010). Empathy-related responding: Associations with prosocial behavior, aggression, and intergroup relations. Social Issues and Policy Review, 4(1), 143-180.

Febriani, A. (2018). Klithih: Faktor risiko dan developmental pathway pelakunya. Humanitas: Jurnal Psikologi Indonesia, 15(2).

Feng, Z., Zhan, J., Ma, C., Lei, Y., Liu, J., Zhang, W., \& Wang, K. (2018). Is cognitive intervention or forgiveness intervention more effective for the reduction of driving anger in Chinese bus drivers? Transportation Research Part F: Traffic Psychology and Behaviour, 55, 101-113.

Fountain, S. (1999). Peace education in UNICEF. Unicef, Programme Division.

Galtung, J. (1967). Theories of peace: A synthetic approach to peace thinking (Vol. 2). International Peace Research Institute.

García-Sancho, E., Salguero, J. M., \& Fernández-Berrocal, P. (2017). Ability emotional intelligence and its relation to aggression across time and age groups. Scandinavian Journal of Psychology, 58(1), 43-51.

Greene, M. B. (2005). Reducing violence and aggression in schools. Trauma, Violence, \& Abuse, 6(3), 236-253.

Healey, M. C. (1967). Aggression and self-regulation of population size in deermice. Ecology, 48(3), 377-392.

Hill, N. (2007). Grow rich! With peace of mind. Penguin.

Hurlock, E. B. (2001). Developmental psychology. Tata McGraw-Hill Education.

Kaczmarek, P. (2006). Counseling psychology and strength-based counseling: A promise yet to fully materialize. The Counseling Psychologist, 34(1), 90-95.

Kartadinata, S., Affandi, I., Wahyudin, D., \& Ruyadi, Y. (2015). Pendidikan kedamaian. Bandung: PT. Remaja Rosdakarya. 
Kaukiainen, A., Björkqvist, K., Lagerspetz, K., Österman, K., Salmivalli, C., Rothberg, S., \& Ahlbom, A. (1999). The relationships between social intelligence, empathy, and three types of aggression. Aggressive Behavior: Official Journal of the International Society for Research on Aggression, 25(2), 81-89.

Keller, J., Hurst, M., \& Uskul, A. (2008). Prevention-focused self-regulation and aggressiveness. Journal of Research in Personality, 42(4), 800-820.

Klein, J., Cornell, D., \& Konold, T. (2012). Relationships between bullying, school climate, and student risk behaviors. School Psychology Quarterly, 27(3), 154.

Lavafpour Noori, F., Zahrakar, K., \& Sanai Zaker, B. (2012). A study of effectiveness of group forgiveness therapy in reducing aggression among 11-13 year old male adolescents in city of dezful. SSU_Journals, 20(4), 489500.

Lee, Y.-C., Lin, Y.-C., Huang, C.-L., \& Fredrickson, B. L. (2013). The construct and measurement of peace of mind. Journal of Happiness Studies, 14(2), 571-590.

Macaskill, A., Maltby, J., \& Day, L. (2002). Forgiveness of self and others and emotional empathy. The Journal of Social Psychology, 142(5), 663-665.

Makewa, L. N., Role, E., Role, J., \& Yegoh, E. (2011). School climate and academic performance in high and low achieving schools: Nandi Central District, Kenya. International Journal of Scientific Research in Education, 4(2), 93-104.

Mappiare, A. (2013). Tipe-tipe metode riset kualitatif untuk eksplanasi sosial budaya dan bimbingan konseling. Malang: Elang Emas Bersama Prodi Bimbingan dan Konseling.

McCallum, R. (2012). Ideologies of identity in adolescent fiction: The dialogic construction of subjectivity. Routledge.

Meeus, W. (2011). The study of adolescent identity formation 2000-2010: A review of longitudinal research. Journal of Research on Adolescence, 21(1), 75-94.

Mehta, S. B., Cornell, D., Fan, X., \& Gregory, A. (2013). Bullying climate and school engagement in ninth-grade students. Journal of School Health, 83(1), 45-52.

Milam, A. J., Furr-Holden, C. D. M., \& Leaf, P. J. (2010). Perceived school and neighborhood safety, neighborhood violence and academic achievement in urban school children. The Urban Review, 42(5), 458-467.

Miles, M. B., \& Huberman, A. M. (1994). An expanded sourcebook qualitative data analysis. SAGE Publication, Inc.

Moore, M., \& Dahlen, E. R. (2008). Forgiveness and consideration of future consequences in aggressive driving. Accident Analysis \& Prevention, 40(5), 1661-1666.

Nadjib, E. A. (2012). Markesot bertutur lagi. Mizan Pustaka.

Nickerson, A. B., Singleton, D., Schnurr, B., \& Collen, M. H. (2014). Perceptions of school climate as a function of bullying involvement. Journal of Applied School Psychology, 30(2), 157-181.

Papalia, D. E., Gross, D. L., \& Feldman, R. D. (2003). Child development: A topical approach. McGraw-Hill Humanities, Social Sciences \& World Languages.

Park, N., \& Peterson, C. (2008). Positive psychology and character strengths: Application to strengths-based school counseling. Professional School Counseling, 12(2), 85-92.

Renati, R., Cavionia, V., \& Zanetti, M. A. (2011). 'Miss, I got mad today!'The Anger Diary, a tool to promote emotion regulation. The International Journal of Emotional Education, 3(1), 48-69.

Roberton, T., Daffern, M., \& Bucks, R. S. (2012). Emotion regulation and aggression. Aggression and Violent Behavior, 17(1), 72-82.

Rosen, Y., \& Salomon, G. (2011). Durability of peace education effects in the shadow of conflict. Social Psychology of Education, 14(1), 135-147.

Routt, G., \& Anderson, L. (2011). Adolescent violence towards parents. Journal of Aggression, Maltreatment \& Trauma, 20(1), 1-19.

Sagkal, A. S., Turnuklu, A., \& Totan, T. (2012). Empathy for interpersonal peace: Effects of peace education on empathy skills. Educational Sciences: Theory and Practice, 12(2), 1454-1460.

Saputra, W. E. S., \& Handaka, I. B. (2017). Konseling kedamaian: Strategi konselor untuk mereduksi perilaku agresi remaja. In Prosiding Seminar Nasional Pendidikan Pancasila dan Kewarganegaraan III.

Saputra, W. N. E., \& Handaka, I. B. (2018). Perilaku agresi pada siswa SMK di Yogyakarta. Jurnal Fokus Konseling, 4(1), 1-8. 
Saputra, W. N. E., Hanifah, N., \& Widagdo, D. N. (2017). Perbedaan tingkat perilaku agresi berdasarkan jenis kelamin pada siswa sekolah menengah kejuruan Kota Yogyakarta. Jurnal Kajian Bimbingan dan Konseling, 2(4), 142-147.

Saputra, W., Supriyanto, A., Astuti, B., \& Ayriza, Y. (2019). Bimbingan kedamaian: Strategi konselor mereduksi agresivitas. Yogyakarta: K-Media.

Sarmini, M., Kurniyatuti, N., \& Sukartiningsih, S. (2018). Klithih: Invisible crime by teenagers. 1st International Conference on Social Sciences (ICSS 2018).

Sarwono, R. B. (2017). Mengendalikan kegaduhan sosial "klithih" dengan ketahanan keluarga. In Proceeding seminar dan lokakarya nasional bimbingan dan konseling 2017 (pp. 190-201).

Smith, E. J. (2006a). The strength-based counseling model. The Counseling Psychologist, 34(1), 13-79.

Smith, E. J. (2006b). The strength-based counseling model: A paradigm shift in psychology. The Counseling Psychologist, 34(1), 134-144.

Steffgen, G., Recchia, S., \& Viechtbauer, W. (2013). The link between school climate and violence in school: A meta-analytic review. Aggression and Violent Behavior, 18(2), 300-309.

Steiner, T. (2009). Trust client strengths. The Art of Solution Focused Therapy, 217.

Tidwell, A. (2004). Conflict, peace, and education: A tangled web. Conflict Resolution Quarterly, 21(4), 463-470.

Ungar, M. (2006). Strengths-based counseling with at-risk youth. Corwin Press.

Valle, M. F., Huebner, E. S., \& Suldo, S. M. (2006). An analysis of hope as a psychological strength. Journal of School Psychology, 44(5), 393-406.

Van der Graaff, J., Branje, S., De Wied, M., \& Meeus, W. (2012). The moderating role of empathy in the association between parental support and adolescent aggressive and delinquent behavior. Aggressive Behavior, 38(5), 368-377.

Wang, W., Vaillancourt, T., Brittain, H. L., McDougall, P., Krygsman, A., Smith, D., Cunningham, C. E., Haltigan, J. D., \& Hymel, S. (2014). School climate, peer victimization, and academic achievement: Results from a multi-informant study. School Psychology Quarterly, 29(3), 360.

White, V. E. (2002). Developing counseling objectives and empowering clients: A strength-based intervention. Journal of Mental Health Counseling, 24(3), 270.

Wiley, R. E., \& Berman, S. L. (2013). Adolescent identity development and distress in a clinical sample. Journal of Clinical Psychology, 69(12), 1299-1304.

Zimmerman, B. J. (2000). Attaining self-regulation: A social cognitive perspective. In Handbook of self-regulation (pp. 13-39). Elsevier. 